\title{
Smoking Modulates Neuroendocrine Responses to Ipsapirone in Patients with Panic Disorder
}

\author{
A. Broocks, M.D., Ph.D., B. Bandelow, M.D., Ph.D., K. Koch, U. Bartmann, J. Kinkelbur, M.D., \\ U. Schweiger, M.D., Ph.D., F. Hohagen, M.D., Ph.D., and G. Hajak, M.D., Ph.D.
}

Reduced 5-HT1A-receptor responsiveness has been reported in patients with panic disorder(PD) and/or agoraphobia (PDA). Although many of these patients are regular smokers, it has not been examined whether psychological or neurobiological effects induced by the selective 5-HT1Areceptor agonist, ipsapirone, are affected by the smoking status of the patients.

In order to clarify this question neuroendocrine challenges with oral doses of ipsapirone $(0.3 \mathrm{mg} / \mathrm{kg})$ and placebo were performed in 39 patients with PDA, and results were compared between patients who smoked ( $>10$ cigarettes per day, $n=17$ ) and patients who had been nonsmokers for at least two years $(n=22)$.

Patients who were smokers (but did not smoke during the challenge procedure) had significantly reduced baseline concentrations of cortisol and a significantly lower body temperature. In comparison to placebo, administration of ipsapirone was associated with significant increases of various psychological symptoms and plasma cortisol concentrations. The subgroup of PD patients who were smokers showed significantly higher cortisol responses to ipsapirone than non-smokers.

In conclusion, smoking status has to be taken into account when assessing the responsiveness of 5-HT1A receptors in patients with psychiatric disorders. The prevention of smoking during challenge sessions might not be the ideal approach in heavy smokers, since sudden abstinence from smoking is likely to affect neurobiological and possibly psychological responses to ipsapirone.

[Neuropsychopharmacology 27:270-278, 2002] (C) 2002 American College of Neuropsychopharmacology. Published by Elsevier Science Inc.
KEY WORDS: Smoking; Nicotine; Serotonin; Ipsapirone; Panic disorder

From the Department of Psychiatry and Psychotherapy, University of Lübeck, 23538 Lübeck, Germany, and the Department of Psychiatry and Psychotherapy, University of Göttingen, 37075 Göttingen, Germany.

Address correspondence to: Dr. A. Broocks, The Department of Psychiatry and Psychotherapy, University of Lübeck, Ratzeburger Allee 160, 23538 Lübeck, Germany. Tel.: +49-451-5002445; Fax. + 49-4515002603; E-mail: broocks.a@psychiatry.mu-luebeck.de

Received June 7, 2001; revised November 16, 2001; accepted January 10,2002

Online publication: $1 / 28 / 02$ at www.acnp.org/citations/ Npp12802234.
Neuropharmacological challenges with the selective 5-hydroxytryptamine-1A (5-HT1A) receptor agonist, ipsapirone, have been used in several studies to assess 5-HT1A-receptor related functions in patients suffering from various neuropsychiatric disorders (Broocks et al. 2000; Lesch et al. 1990a; Lesch et al. 1991; Lesch et al. 1990b; Lesch et al. 1992) and in healthy controls (Broocks et al. 1999; Kahn et al. 1994; Lesch et al. 1990c; Lesch et al. 1990d).

Indices of abnormal serotonergic function have been reported in patients with panic disorder (PD) and/or agoraphobia (PDA). In particular, there is evidence for an increased sensitivity of the $5-\mathrm{HT}_{2 \mathrm{C}}$ subsystem (Charney et al. 1987a; Charney et al. 1987b; Kahn et al. 1988a; 
Kahn and Wetzler 1991; Kahn et al. 1988b). In contrast, stimulation of $5-\mathrm{HT}_{1 \mathrm{~A}}$ receptors by ipsapirone was followed by an attenuated hypothermic and $\mathrm{ACTH} /$ cortisol response in patients with PDA (Broocks et al. 2000; Lesch et al. 1992).

In healthy controls, ipsapirone produces dose-dependent increases in plasma cortisol and ACTH as well as dose-dependent reductions in body temperature (Cowen 2001; Kahn et al. 1994; Lesch et al. 1989). Ipsapirone acts on specific serotonergic mechanisms in the brain through its high-affinity binding to the $5-\mathrm{HT}_{1 \mathrm{~A}}$ receptor subtype. The binding sites are predominantly located on serotonergic neurons in the raphe nuclei (presynaptic autoreceptors) and in limbic structures (postsynaptic receptors). Agonistic properties at presynaptic somatodendritic sites have been observed, resulting in decreased serotonergic neurotransmission (Peroutka 1985). Concerning the high selectivity of ipsapirone, it has to be considered that the metabolite 1-(2-pyrimidinyl)-piperazine (1-PP) has been found to exert antagonistic effects at pre- and postsynaptic $\alpha 2$-adrenoceptors (Blier et al. 1991; Miller et al. 1992).

Several lines of evidence suggest that serotonergic neurotransmission, including the regulation of 5-HT1A receptors, is affected by nicotine (Benwell et al. 1990; Kenny et al. 2001). Recent studies show that some of nicotine's psychotropic and endocrine effects are exerted by stimulation of 5-HT1A receptors on dorsal raphe neurons (Cheeta et al. 2001; Mihailescu et al. 2001).

There is a high incidence of smoking in patients with anxiety and other psychiatric disorders (Breslau et al. 1993; Glassman 1993; Kendler et al. 1993; Marks et al. 1997; Miller and Gold 1998; Sellman et al. 1999). To our knowledge, no clinical studies have examined the question of whether psychological or neurobiological effects induced by serotonergic agents such as ipsapirone are affected by the smoking status of a patient. Many challenge studies do not report the smoking status of their patient sample. Because control subjects are usually required to be nonsmokers, the presence of a subgroup of smokers within the patient sample might well represent an important confounding factor, modifying the neuroendocrine and the psychological responses to a given challenge agent. In the present article, we have compared psychological and physiological responses to oral doses of ipsapirone $(0.3 \mathrm{mg} / \mathrm{kg})$ in $17 \mathrm{PD}$ patients who were regular smokers ( $>10$ cigarettes per day) with those of a group of patients who had been nonsmokers for at least two years $(n=22)$.

\section{MATERIALS AND METHODS}

\section{Subjects}

Patients with diagnoses of moderate to severe PD (with or without PDA) according to DSM-IV and ICD-10 criteria (age range: $18-50$ y) were recruited by physician referral and from the Outpatient Anxiety Disorders Unit of the Department of Psychiatry at the University of Göttingen for participation in a treatment study, which has been reported elsewhere (Broocks et al. 1998). Forty out of the 46 patients gave written consent to participate in this study. Diagnoses were made by an experienced psychiatrist using the Structured Clinical Interview for DSM-III-R. The following scales were used to assess the severity of the condition: Hamilton Anxiety Scales (HAMA) (Hamilton 1969), Bandelow Panic and Agoraphobia Scale (observer-rated version: BPAS-O, patient-rated version: BPAS-P (Bandelow 1995), Clinical Global Impression (rater version: CGI, patient version: PGI (NIMH 1976). Exclusion criteria were pregnancy, lactation, significant medical illness, bipolar affective disorder, psychotic symptoms, drug dependency (alcohol, benzodiazepine, or other), anorexia or bulimia nervosa, and body weight below $80 \%$ of ideal body weight. All patients were in good physical health and had a normal physical examination, electrocardiogram, and routine laboratory tests (renal, hepatic, pancreatic, hematological, and thyroid functions) prior to inclusion in the study. Patients taking psychotropic medication were required to discontinue this medication at least three wk before baseline. During this time, only single doses of promethazine $(25-50 \mathrm{mg}$ ) were allowed in the event of severe panic attacks. No medication was allowed $48 \mathrm{~h}$ prior to the challenge. Urine analysis for benzodiazepine intake was performed in all patients. For statistical analysis, patients were divided into two groups: non-smokers $(n=22)$, who were required to have been abstinent for at least two $y$, and smokers $(n=17)$, who were defined as having a regular habit of smoking more than 10 cigarettes per day for at least six mos (average number of daily cigarettes was 17 , with a range of 10-40 cigarettes per day). One patient was excluded from the statistical analysis, because she smoked only 5-10 cigarettes per day.

After the entire procedure had been explained, all participants gave written informed consent. All procedures have been carried out in accordance with the Declaration of Helsinki. The trial was approved by the Ethics Committee of the Medical Faculty of the University of Göttingen. There was no financial support from any commercial organizations.

\section{Challenge procedures}

All patients participated in two challenge sessions conducted in a randomized double-blind fashion on separate days with an interval of at least $48 \mathrm{~h}$ between the two challenges.

Because the cortisol baseline secretion is known to be more stable during the afternoon, the procedure was performed in the afternoon. On the day of each challenge session, subjects arrived at the sleep laboratory of 
the Department of Psychiatry at approximately $12: 30 \mathrm{~h}$ for a standardized meal. During the challenge sessions, subjects abstained from eating, drinking, or sleeping, and remained supine with the head elevated. Smoking was not permitted on the study day. At 13:00 h, an intravenous catheter was inserted into an antecubital vein for repeated blood sampling. At 14:30 h, 2-4 capsules of either ipsapirone $(0.3 \mathrm{mg} / \mathrm{kg})$ or placebo were administered orally in a randomized, double-blind manner.

Behavioral effects were assessed using a modified version of the NIMH Self-Rating Scale that comprises 24 questions and defines six subscales of behavioral change: anxiety, activation-euphoria, altered self-reality, depressive affect, dysphoria, and functional deficit (Murphy et al. 1989). In addition, anxiety ratings were also assessed by the Acute Panic Inventory (Dillon et al. 1987). Behavioral ratings were completed at 14:00, 14:30, 15:00, 15:30, 16:00, 16:30, 17:30, and 18:30 h.

Baseline blood samples were drawn at 14:00 and at 14:30 h (immediately prior to capsule intake), and serial blood draws were subsequently made at 15:00, 15:30, 16:00, 16:30, 17:30, and 18:30 h. Samples of blood were immediately placed on ice, centrifuged within $15 \mathrm{~min}$ of collection, and the plasma stored at $-80^{\circ} \mathrm{C}$ until assay. Plasma samples were assayed for cortisol, prolactin, noradrenaline, adrenaline, and plasma concentrations of ipsapirone.

Throughout each challenge session, oral temperature as well as blood pressure and heart rate were measured at 30-min intervals. At the end of the procedure, subjects were asked whether they had experienced any psychological or somatic symptoms during the afternoon. If so, they were further asked whether these symptoms were identical or at least very similar to panic attacks.

Plasma concentrations of ipsapirone were measured by HPLC and UV detection. Prolactin and cortisol were determined by ELISA (Immundiagnostica Enzym Test ${ }^{\mathrm{TM}}$ Cortisol (\# 1288946) and Prolactin (\# 1448609), Boehringer-Mannheim, Germany). The interassay variability was $6.5-7.5 \%$ for prolactin and $6.2-7.9 \%$ for cortisol.

\section{Data analysis}

The maximum difference of a response parameter was determined to be the primary response criterium. It was calculated individually using the greatest positive difference between the baseline value and each of the six time-points following the administration of the challenge agent. Exact Wilcoxon analysis was used to compare the maximal response to ipsapirone to the maximal response observed after placebo intake, repectively. This statistitical approach was chosen because analyses that include all time-points can mask differences in maximal response that may occur at only one time, and because differences in resorption lead to a high variability concerning the time course of changes in oral studies.
Exact Wilcoxon analysis was also performed to compare the behavioral, neuroendocrine, and temperature changes induced by ipsapirone in patients who smoked with those in patients who did not. To assess temperature changes after administration of ipsapirone, maximal decreases of temperature were calculated.

The baseline values for all psychobehavioral and neuroendocrine data on the two challenge days were used to calculate a mean baseline value for every subject. In a second step, these means were used to compare baseline variables of smokers with those of non-smokers by exact Wilcoxon analysis. $p$-values were adjusted by the Bonferroni-Holm method. Categorical data were compared by means of Fisher's Exact Test. Two-tailed tests were used throughout. All statistical analyses were performed by means of SAS 8.0 software (SAS 1989).

\section{RESULTS}

\section{Comparability of Severity of PD and/or Agoraphobia in Smokers and Nonsmokers}

There were no statistical differences in terms of age and sex distribution between the two patient groups (Table 1). Average values on the psychometric scales show that patients in both groups suffered from PDA of a moderate to severe degree. Symptom severity as measured by two self-rating scales (BAI and BDI), and two observer-rated scales (HAMA and MADRS) did not reveal any significant differences between smoking and nonsmoking patients. There was a nonsignificant trend indicating somewhat higher depression ratings in the subgroup of smokers ( $p=.07$, exact Wilcoxon analysis). Symptom severity was assessed prior to starting a treatment of PD that was usually done in the week following the two challenge sessions.

Plasma concentrations of ipsapirone measured across the challenge procedure, with the maximum values observed $90 \mathrm{~min}$ after drug intake $(43.6 \pm 18.7 \mu \mathrm{g} / \mathrm{l}$ in

Table 1. Demographic and Psychopathological Data of Patients with Panic Disorder with or without Agoraphobia (PDA), Divided into Smokers $(n=17)$ and Nonsmokers $(n=22)$

\begin{tabular}{lccc}
\hline Patients with PDA & $\begin{array}{c}\text { Smokers } \\
(\mathbf{n}=\mathbf{1 7})\end{array}$ & $\begin{array}{c}\text { Nonsmokers } \\
(\mathbf{n}=\mathbf{2 2})\end{array}$ & $\boldsymbol{p}$ \\
\hline Age (y) & $31.5 \pm 10.9$ & $33.1 \pm 9.2$ & $\mathrm{~ns}$ \\
Sex, No. M/F & $10 / 7$ & $10 / 12$ & $\mathrm{~ns}$ \\
Psychopathology & & & \\
$\quad$ HAMA & $23.2 \pm 9.0$ & $22.1 \pm 7.3$ & 0.53 \\
BAI & $36.5 \pm 18.6$ & $30.9 \pm 11.2$ & 0.27 \\
MADRS & $20.1 \pm 6.7$ & $16.4 \pm 8.4$ & 0.07 \\
BDI & $19.7 \pm 10.1$ & $13.9 \pm 7.5$ & 0.07 \\
\hline
\end{tabular}

Data as mean \pm standard deviation; statistical comparison was performed by exact Wilcoxon analysis (two-tailed test), and a modified version of Fisher's exact test for contingency tables (sex). ns = not significant. 
smokers and $38.1 \pm 13.2 \mu \mathrm{g} / 1$ in nonsmokers). This was followed by a gradual decline with nearly identical ipsapirone levels $180 \mathrm{~min}$ and $240 \mathrm{~min}$ after drug intake. Statistical analysis by ANOVA did not reveal any significant differences between smokers and nonsmokers with regard to plasma concentration changes of ipsapirone.

\section{Comparison of Psychobehavioral and Neuroendocrine Variables at Baseline}

Table 2 shows mean baseline values for behavioral and hormonal data calculated from the baseline parameters of the two challenge days. The subgroup of PDA patients who, though smokers, were not allowed to smoke before and during the challenge sessions, had significantly lower plasma concentrations of cortisol and a significantly lower body temperature than the nonsmokers. They also showed a statistical trend $(p=.066)$ toward decreased prolactin levels.

\section{Psychobehavioral Responses to Ipsapirone}

In nearly all patients, intake of ipsapirone was followed by various psychological and physical symptoms such as dizziness, anxiety, nausea, dysphoria, altered self-reality, and drowsiness. Symptoms were most pronounced 30-90 min after intake. In both smokers and nonsmokers, about half of the patients experienced pronounced anxiety that was described to be identical or at least very similar to naturally occurring panic attacks. Statistical comparison of the ipsapirone and the placebo challenge revealed that administration of ipsapirone was followed by a significant increase of self-rated anxiety, activation, dysphoria, and functional deficits in both smokers and nonsmokers $(p<.05$, exact Wilcoxon analysis, Figure 1). A significant increase in activation was

Table 2. Baseline Psychobehavioral and Neuroendocrine Variables in Patients with Panic Disorder with or without Agoraphobia (PDA), Divided into Smokers $(n=17)$ and Nonsmokers $(\mathrm{n}=22)$

\begin{tabular}{lrrr}
\hline & $\begin{array}{c}\text { Smokers } \\
(\mathbf{n}=\mathbf{1 7})\end{array}$ & $\begin{array}{c}\text { Nonsmokers } \\
(\mathbf{n}=\mathbf{2 2})\end{array}$ & $\boldsymbol{p}$ \\
\hline NIMH Scale (Score) & & & \\
$\quad$ Activation & $1.98 \pm 3.5$ & $1.79 \pm 3.6$ & 0.40 \\
$\quad$ Altered Self-Reality & $2.1 \pm 3.9$ & $2.8 \pm 5.5$ & 0.95 \\
Anxiety & $3.98 \pm 6.6$ & $5.16 \pm 6.6$ & 0.68 \\
$\quad$ Depression & $3.0 \pm 5.1$ & $3.71 \pm 5.6$ & 0.58 \\
Dysphoria & $1.87 \pm 3.2$ & $1.66 \pm 3.0$ & 0.71 \\
$\quad$ Functional Deficit & $2.95 \pm 4.1$ & $2.59 \pm 3.6$ & 0.57 \\
Hormones & & & \\
$\quad$ Cortisol $(\mu \mathrm{g} / \mathrm{dl})$ & $6.59 \pm 2.72$ & $12.15 \pm 6.79$ & 0.001 \\
$\quad$ Prolactin $(\mu \mathrm{U} / \mathrm{ml})$ & $127.6 \pm 83.8$ & $162.5 \pm 62.9$ & 0.066 \\
$\quad$ Body Temperature $\left({ }^{\circ} \mathrm{C}\right)$ & $36.61 \pm 0.35$ & $36.84 \pm 0.32$ & 0.025 \\
\hline
\end{tabular}

Data as mean \pm standard deviation; statistical comparison was performed by exact Wilcoxon analysis (two-tailed test). observed only in nonsmokers, whereas increased depressive symptoms were reported only by the group of smokers. In summary, no significant differences could be detected when the psychobehavioral responses of smokers were directly compared with those of nonsmokers (Figure 1). Accordingly, no significant differences between smokers and nonsmokers were observed when the Acute Panic Inventory was used (data not shown).

\section{Neuroendocrine and Temperature Changes}

Figure 2 shows the mean maximal changes in hormone concentrations in patients with PDA after adminstration of ipsapirone or placebo. In comparison with placebo, intake of ipsapirone induced a significant increase of cortisol in both groups of PDA patients (smokers and nonsmokers). There were no significant changes in prolactin levels. In the group of PDA patients who were smokers, the ipsapirone-induced increases of cortisol concentrations were about twice as high as in the nonsmoker group ( $p=.034$, exact Wilcoxon analysis). In addition, body temperature decreased significantly in both patient groups in comparison with the placebo condition. The hypothermic response to ipsapirone seemed to be more pronounced in smokers than in nonsmokers $(p=.053$, exact Wilcoxon analysis).

\section{DISCUSSION}

The major finding of this study is a significantly increased cortisol response to ipsapirone in PDA patients who were smokers but were not allowed to smoke on the challenge day compared with nonsmoking patients suffering from PDA of comparable severity. In addition, a positive smoking status was associated with markedly reduced baseline concentrations of cortisol and a significantly reduced body temperature preceding administration of ipsapirone or placebo. Plasma concentrations of ipsapirone were not different between smoking and nonsmoking patients. Because changes in cortisol secretion and body temperature are considered as two important endpoints in neuroendocrine challenge paradigms assessing $5-\mathrm{HT}_{1 \mathrm{~A}}$ receptor-related functions, these results emphasize the necessity to pay regard to the smoking status of the patient sample.

\section{Psychoneuroendocrine Effects of Smoking and Smoking Cessation}

Habitual smokers had significantly elevated salivary cortisol levels after having smoked two cigarettes (Kirschbaum et al. 1992). This stimulating effect of smoking on cortisol secretion is likely to be related to the neuropharmacological actions of nicotine, as intravenous administration of nicotine produces a dose-dependent increase in cortisol 

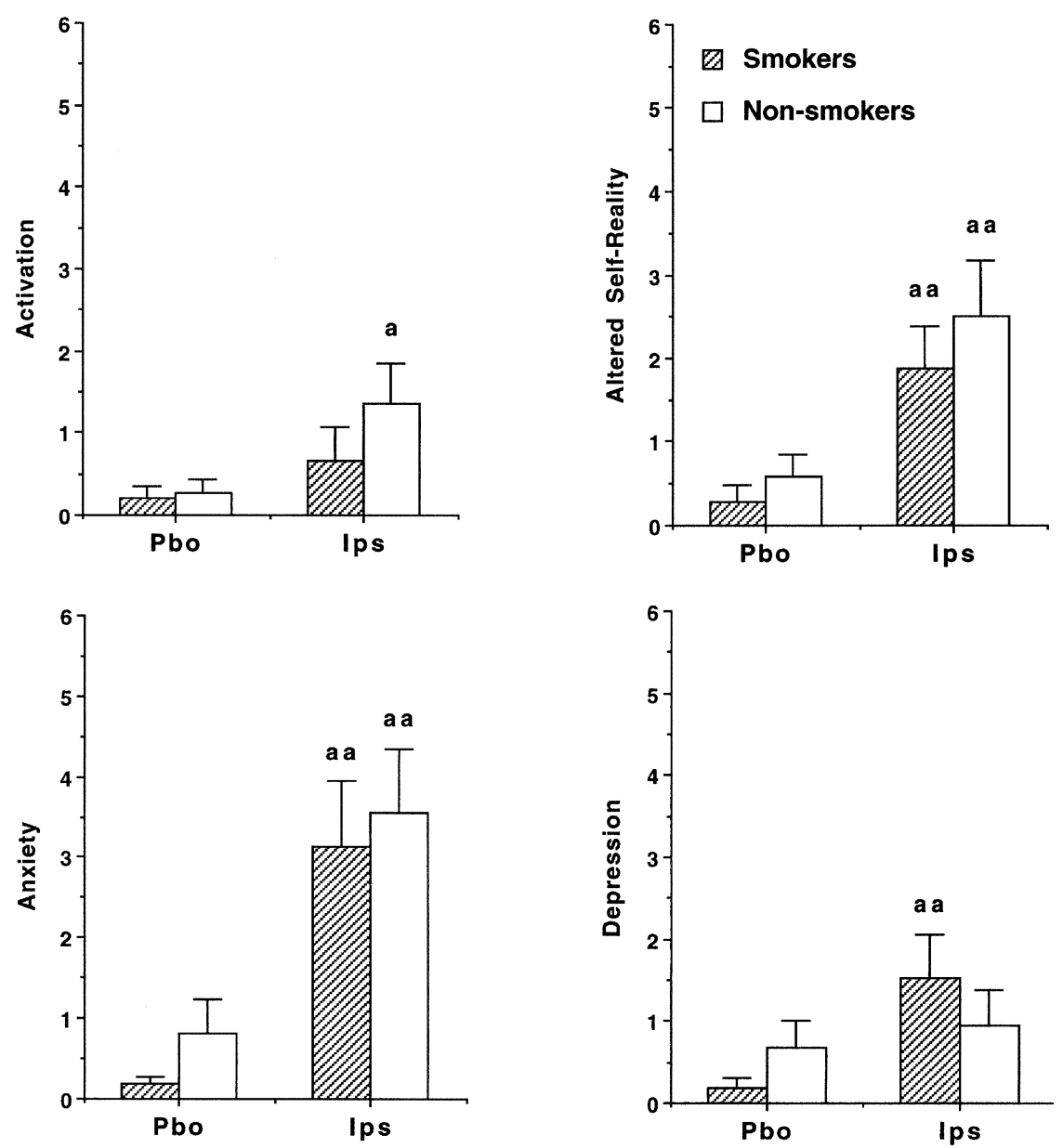

Figure 1. Maximum increase $\left(\mathrm{C}_{\max }\right)$ in self-rated psychological symptoms as measured by the NIMH Rating Scale following the administration of ipsapirone and placebo in patients with panic disorder and/or agoraphobia, divided into smokers $(\mathrm{n}=17)$ and nonsmokers $(\mathrm{n}=$ 22). Comparisons were done with the Wilcoxon-Mann-Whitney test. Data shown as mean \pm SEM. $\mathbf{a}=$ Ips vs Pbo, $p<.05$; $\mathbf{a a}=p<.01 ; \mathbf{a a a}=p<.001$.
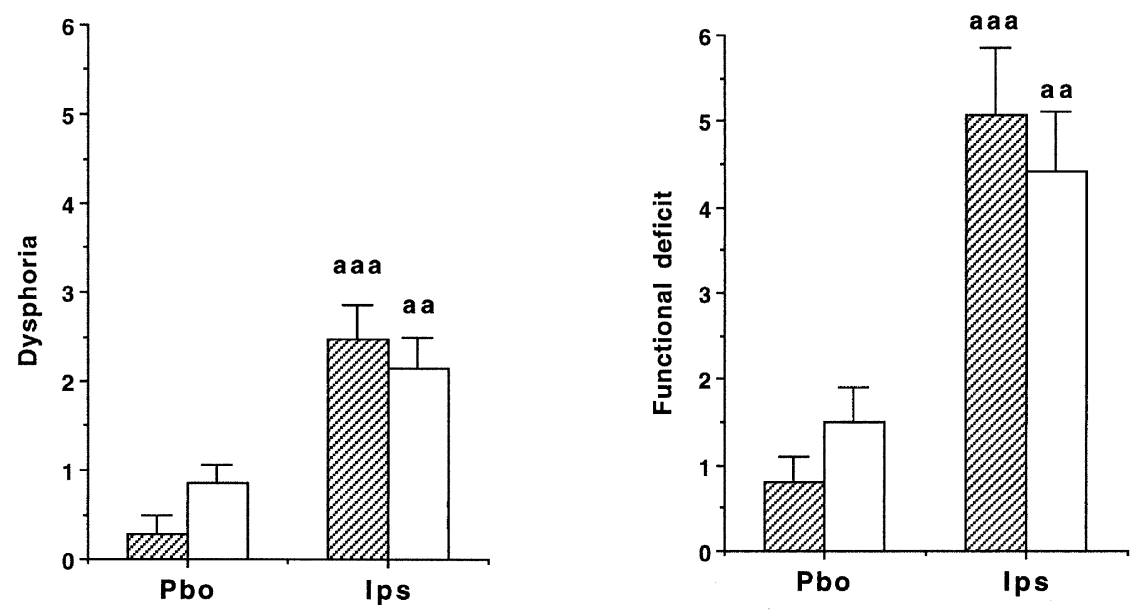

and ACTH in human subjects (Newhouse et al. 1990). These effects were accompanied by increased anxiety and a decrease in mood ratings (Newhouse et al. 1990). In contrast to the acute effects of nicotine, chronic exposition was associated with a decreased basal secretion of ACTH and cortisol in animal experiments (Balfour 1989). Accordingly, one way of explaining our findings consist of the hypothesis that smokers might repeatedly stimulate their HPA axis during the day. In order to avoid hypercortisolism, counter-regulatory mechanisms are likely to be activated in smokers. Because of these mechanisms, sudden abstinence from smoking might result in low cortisol levels, as observed in the present study.

DSM-IV has included a nicotine withdrawal syndrome that is characterized by craving for cigarettes, irritability, anxiety, inner tension, and concentration difficulties. These symptoms are usually observed within the first two weeks after sudden cessation of smoking, although some can be experienced as early as $4-6 \mathrm{~h}$ after the last cigarette. The present data suggest that the 

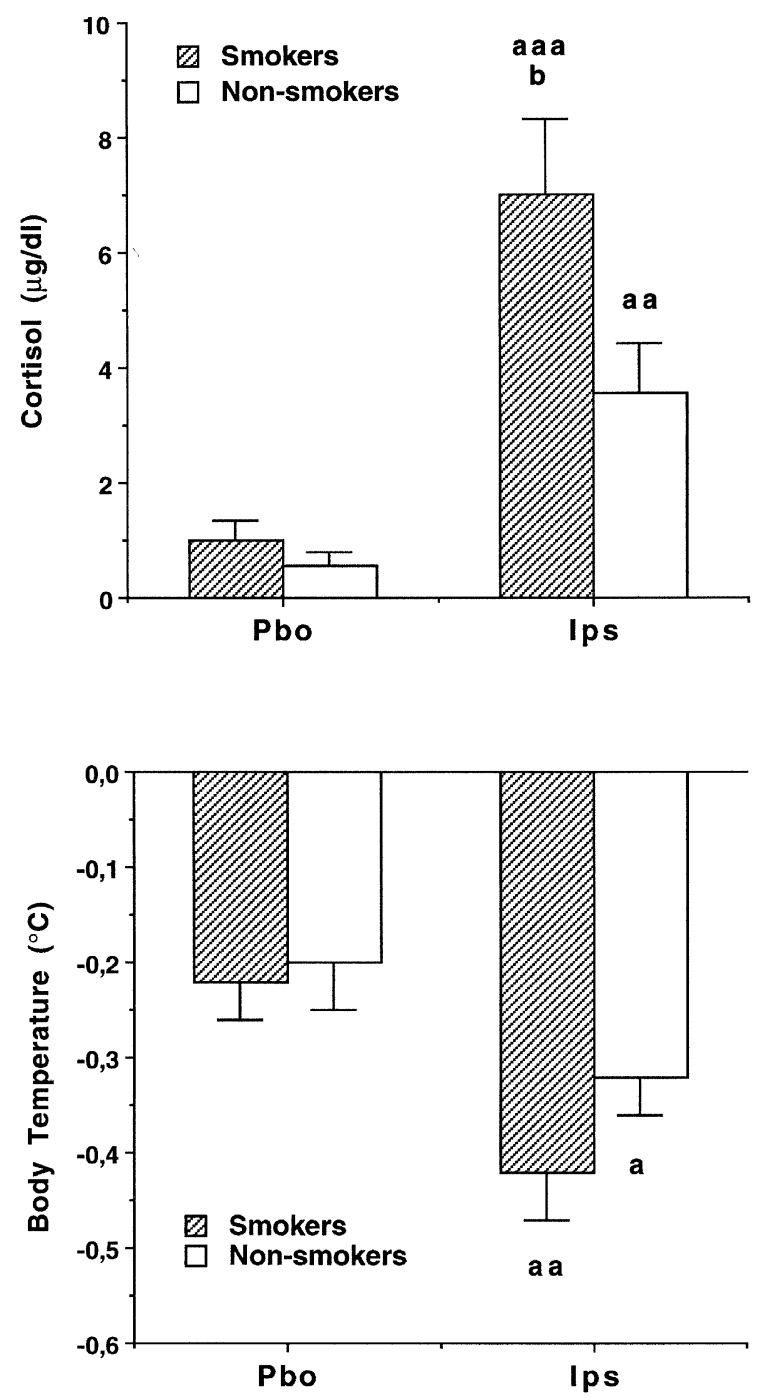

Figure 2. Maximum increase of plasma cortisol and maximum decrease of body temperature following the administration of ipsapirone and placebo in patients with panic disorder and/or agoraphobia, divided into smokers $(\mathrm{n}=17)$ and nonsmokers $(n=22)$. Comparisons were done with the WilcoxonMann-Whitney test. Data shown as mean \pm SEM. $\mathbf{a}=$ Ips vs Pbo, $p<.05 ; \mathbf{a a}=p<.01 ; \mathbf{b}=$ smokers vs non-smokers, $p<.05$.

patients who were smokers but were prevented from smoking did not suffer from a significant withdrawal syndrome at the time of the challenge procedure. Because the patients were not allowed to smoke on the challenge day, all of the smokers reported that they had had their last cigarette the prior evening. One of the limitations of our study is that abstinence from smoking on the challenge day was verified only by self-report and could not be controlled objectively as the patients arrived at the laboratory at noon. Nevertheless, based on the known stimulating effects of nicotine on cortisol secretion, the markedly reduced cortisol concentrations at baseline are likely to be a neuroendocrine consequence of abstinence from smoking. Such neuroendocrine changes might well precede any psychological withdrawal symptoms. We hypothesize that smokers depend on their daily number of cigarettes in order to maintain an adequate activity of the HPA axis.

\section{Interaction of Smoking with the Serotonergic Neurotransmitter System}

In a human postmortem study (Benwell et al. 1990), smokers were characterized by significantly decreased concentrations of 5-HT and 5-HIAA in several brain regions (hippocampus, nucleus raphe, rectal gyrus). In addition, the density of 5-HT1A receptors appeared to be increased in the hippocampus of smokers (Benwell et al. 1990). The authors conclude that some of the psychotropic effects of smoking might be mediated by serotonergic receptors. In male rats, acute nicotine withdrawal was associated with a significant elevation of the auditory startle response. This effect could be blocked by pretreatment with 5-HT-1A antagonists, indicating that 5-HT-1A receptors play a role in the neurophysiology of nicotine withdrawal (Rasmussen et al. 1997). Recent studies show that some of nicotine's psychotropic and endocrine effects are exerted by stimulation of 5-HT1A receptors on dorsal raphe neurons (Cheeta et al. 2001; Mihailescu et al. 2001), and that 5-HT1A receptor gene expression in the cerebral cortex and dorsal hippocampus is regulated by nicotine (Kenny et al. 2001).

Smokers often report that smoking a cigarette has a calming effect in stressful situations (Gilbert 1979), and that it might improve concentration. However, it has been argued that the stress perceived by smokers results from withdrawal effects that are relieved by selfadministration of nicotine (Richmond 1994). In a recent PET study, IV nicotine induced a dose-dependent increase in several behavioral parameters, including feelings of "rush", "high," and "drug liking." Nicotine also induced a dose-dependent increase in neuronal activity in distributed brain regions, including the nucleus accumbens, amygdala, cingulate, and frontal lobes (Stein et al. 1998). Activation of these structures is consistent with nicotine's behavior-arousing and behavior-reinforcing properties in humans. The observation that ipsapirone evoked depressive symptoms only in the smokers with PDA is reminiscent of studies reporting that sudden abstinence from smoking leads to depressive symptoms in many smokers and has been associated with relapse in patients with a history of major depression (Breslau et al. 1998; Tsoh et al. 2000). There is evidence that the use of bupropion decreases the risk of relapse in these patients (Patten et al. 1999). Data from a recent study suggest that prior smoking might predispose to occurrence of panic attacks (Breslau and Klein 1999), but further research is required to elucidate the relationship between smoking and the development or maintenance of PD. 
Ipsapirone induces cortisol secretion via release of ACTH rather than by direct action on the adrenal gland (Przegalinski et al. 1989). The assumption that ipsapirone's hypothermic effect and the stimulation of ACTH and cortisol primarily reflect $5-\mathrm{HT}_{1 \mathrm{~A}}$ receptor function is also supported by the observation that these responses can be antagonized by $5-\mathrm{HT}_{1 \mathrm{~A}}$ receptor antagonists (Goodwin et al. 1987; Hamon et al. 1987) and by recent findings confirming the utility of hypothermia as a robust in-vivo probe of 5-HT-1A receptor function (Cryan et al. 1999; Oerther and Ahlenius 2001). However, further studies are necessary to clarify whether cortisol and temperature responses are mediated by different mechanisms (Cowen 2001).

\section{The Hypothalamic-Pituitary-Adrenal System in PD}

In normal individuals, stress conditions result in elevated cortisol concentrations in plasma (Hellhammer 1989). Because patients with PD suffer from acute attacks of anxiety and sometimes from constant anticipatory anxiety, it has been speculated that cortisol levels would be increased temporarily or permanently in these patients. In fact, there is some evidence that the hypothalamic pituitary-adrenal (HPA) system is overactive in patients with PD, but up to now the data have been inconclusive. Baseline plasma levels of cortisol were reported to be elevated in panic patients by some authors (Goldstein et al. 1987; Nesse et al. 1984; Roy-Byrne et al. 1986). (Hollander et al. 1989) found elevated baseline plasma cortisol levels only in a subgroup of panic patients. Night-time urinary excretion of cortisol, norepinephrine, and epinephrine was significantly elevated in drug-free patients compared with normal individuals (Bandelow et al. 1997; Bandelow et al. 2000b). Measurements were repeated after $4 \mathrm{wks}$, and the same differences were found again (Bandelow et al. 1997). These results were in agreement with an earlier study investigating 24-h secretion of cortisol, which had reported overnight hypercortisolemia (Abelson and Curtis 1996). Recently, we have reported significant elevations of saliva cortisol levels during spontaneously occurring panic attacks (Bandelow et al. 2000a). Other authors, however, found normal baseline plasma levels in panic patients (Brambilla et al. 1992; Cameron et al. 1987; Cameron and Nesse 1988; Liebowitz et al. 1985; Villacres et al. 1987; Woods et al. 1988). One possible explanation for these discrepant findings could be related to the observation from the present study showing that temporary withdrawal from smoking leads to a reduction of baseline cortisol levels, thus masking an overactive HPA axis in PD patients. Other possible confounding factors, however, must also be taken into consideration when explaining discrepant findings of former studies of patients with PD, e.g., reduced motor activity, abnormal eating habits, or comorbid depression. An important limitation of our study is the fact that no control group has been examined with an identical study design. Consequently, it cannot be concluded that similar findings will be present in healthy controls.

\section{Implications for Neuroendocrine Challenge Procedures}

To our knowledge, there are no prior reports that the smoking status of the subjects affects neuroendocrine responses to ipsapirone. PDA patients who were smokers, but not allowed to smoke on the challenge day, showed an increase of cortisol after administration of ipsapirone that was nearly two-fold in magnitude when compared with the cortisol responses of the group of nonsmoking patients. This finding is of great practical relevance. In comparison with the cortisol response to ipsapirone reported in healthy nonsmokers, only the subgroup of PDA patients who are nonsmokers displays a significantly reduced responsiveness of $5-\mathrm{HT}_{1 \mathrm{~A}}$ receptors, which was first described by Lesch et al. (1992).

One way to handle this problem in future studies would be to exclude smokers from neuroendocrine studies assessing $5-\mathrm{HT}_{1 \mathrm{~A}}$ receptor-related functions. But because of the high percentage of smokers among patients with psychiatric disorders, this would be a major obstacle to the recruitment of patients. Alternatively, patient and control samples could be matched not only for sex and age, but also for smoking status. In the latter case it might be advisable to allow smokers to smoke before and during a challenge according to their usual habits in order to prevent any withdrawal effects. Challenge procedures, however, have to be validated with regard to acute smoking effects; this might also lead to a high variability of the psychological and neuroendocrine endpoints in a sample consisting of smokers and nonsmokers.

\section{CONCLUSION}

Sudden abstinence from smoking is associated with a significant reduction of cortisol secretion, a significantly reduced body temperature, and an exaggerated cortisol response to 5-HT1A receptor stimulation by ipsapirone. These results emphasize the importance of controlling for smoking status in neuroendocrine challenge studies that compare patients with different neuropsychiatric disorders or patient samples with control subjects. Smoking has to be considered as a psychopharmacological comedication exerting its own effects on certain brain receptors.

\section{ACKNOWLEDGMENTS}

This research was supported by a public grant from the Volkswagenstiftung, Germany. There is no other financial involvement that might potentially bias this work. 


\section{REFERENCES}

Abelson JL, Curtis GC (1996): Hypothalamic-pituitary-adrenal axis activity in panic disorder: prediction of longterm outcome by pretreatment cortisol levels. Am J Psychiatry 153:69-73

Balfour DJ (1989): Influence of nicotine on the release of monoamines in the brain. Prog Brain Res 79:165-172

Bandelow B (1995): Assessing the efficacy of treatments for panic disorder and agoraphobia. II. The Panic and Agoraphobia Scale. Int Clin Psychopharmacol 10:73-81

Bandelow B, Sengos G, Wedekind D, Huether G, Pilz J, Broocks A, Hajak G, Ruther E (1997): Urinary excretion of cortisol, norepinephrine, testosterone, and melatonin in panic disorder. Pharmacopsychiatry 30: 113-117

Bandelow B, Wedekind D, Pauls J, Broocks A, Hajak G, Rüther E (2000a): Salivary cortisol in panic attacks. Am J Psychiatry 157:454-456

Bandelow B, Wedekind D, Sandvoss V, Broocks A, Hajak G, Pauls J, Peter H, Ruther E (2000b): Diurnal variation of cortisol in panic disorder. Psychiatry Res 95:245-250

Benwell ME, Balfour DJ, Anderson JM (1990): Smokingassociated changes in the serotonergic systems of discrete regions of human brain. Psychopharmacology (Berl) 102:68-72

Blier P, Curet O, Chaput Y, de Moutigay C (1991): Tandospirone and its metabolite, 1-(2-pyrimidinyl)-piperazine-II. Effects of acute administration of 1-PP and longterm administration of tandospirone on noradrenergic neurotransmission. Neuropharmacology 30:691-701

Brambilla F, Bellodi L, Perna G, Battaglia M, Sciuto G, Diaferia G, Petraglia F, Panerai A, Sacerdote P (1992): Psychoimmunoendocrine aspects of panic disorder. Neuropsychobiology 26:12-22

Breslau N, Kilbey MM, Andreski P (1993): Vulnerability to psychopathology in nicotine-dependent smokers: an epidemiologic study of young adults. Am J Psychiatry 150:941-946

Breslau N, Klein DF (1999): Smoking and panic attacks: an epidemiologic investigation. Arch Gen Psychiatry 56:1141-1147

Breslau N, Peterson EL, Schultz LR, Chilcoat HD, Andreski $P$ (1998): Major depression and stages of smoking. A longitudinal investigation. Arch Gen Psychiatry 55:161-166

Broocks A, Bandelow B, George A, Jestrabeck C, Opitz M, Bartmann U, Gleiter CH, Meineke I, Roed IS, Ruther E, Hajak G (2000): Increased psychological responses and divergent neuroendocrine responses to $\mathrm{m}-\mathrm{CPP}$ and ipsapirone in patients with panic disorder. Int Clin Psychopharmacol 15:153-161

Broocks A, Bandelow B, Pekrun G, George A, Meyer T, Bartmann U, Hillmer VU, Ruther E (1998): Comparison of aerobic exercise, clomipramine, and placebo in the treatment of panic disorder. Am J Psychiatry 155:603-609

Broocks A, Meyer T, George A, Hillmer-Vogel U, Meyer D, Bandelow B, Hajak G, Bartmann U, Gleiter CH, Rüther E (1999): Decreased neuroendocrine responses to metachlorophenylpiperazine (m-CPP) but normal responses to ipsapirone in marathon runners. Neuropsychopharmacology 20:150-161

Cameron OG, Lee MA, Curtis GC, McCann DS (1987): Endo- crine and physiological changes during "spontaneous" panic attacks. Psychoneuroendocrinology 12:321-331

Cameron OG, Nesse RM (1988): Systemic hormonal and physiological abnormalities in anxiety disorders. Psychoneuroendocrinology 13:287-307

Charney DS, Woods SW, Goodman WK, Heninger GR (1987a): Neurobiological mechanisms of panic anxiety: biochemical and behavioral correlates of yohimbineinduced panic attacks. Am J Psychiatry 144:1030-1036

Charney DS, Woods SW, Goodman WK, Heninger GR (1987b): Serotonin function in anxiety, II. Effects of the serotonin agonist MCPP in panic disorder patients and healthy subjects. Psychopharmacology (Berl) 9:14-24

Cheeta S, Irvine EE, Kenny PJ, File SE (2001): The dorsal raphe nucleus is a crucial structure mediating nicotine's anxiolytic effects and the development of tolerance and withdrawal responses. Psychopharmacology (Berl) 155:78-85

Cowen PJ (2001): Psychopharmacology of 5-HT(1A) receptors. Nucl Med Biol 27:437-439

Cryan JF, Kelliher P, Kelly JP, Leonard BE (1999): Comparative effects of serotonergic agonists with varying efficacy at the 5-HT(1A) receptor on core body temperature: modification by the selective $5-\mathrm{HT}(1 \mathrm{~A})$ receptor antagonist WAY 100635. J Psychopharmacol 13:278-283

Dillon DJ, Gorman JM, Liebowitz MR, Fyer AJ, Klein DF (1987): Measurement of lactate-induced panic and anxiety. Psychiatry Res 20:97-105

Gilbert DG (1979): Paradoxical tranquilizing and emotionreducing effects of nicotine. Psychol Bull 86:643-661

Glassman AH (1993): Cigarette smoking: implications for psychiatric illness. Am J Psychiatry 150:546-553

Goldstein S, Halbreich U, Asnis G, Endicott J, Alvir J (1987): The hypothalamic-pituitary-adrenal system in panic disorder. Am J Psychiatry 144:1320-1323

Goodwin GM, De Souza RJ, Green AR (1987): Effects of the novel anxiolytics gepirone, buspirone and ipsapirone on free feeding and feeding induced by 8 -OH-DPAT. Psychopharmacology (Berl) 93:349-352

Hamilton M (1969): Diagnosis and rating of anxiety. Br J Psychiat Spec Publ 3:76-79

Hamon M, Gozlan H, Mestikawy SE, Emerit MB, Bolanos F, Schecter L (1987): The CNS Serotonergic System: Progression toward a Collaborative Organization. New York: Raven Press

Hellhammer D (1989): Salivary cortisol and behavior: an overview. Neuropsychobiology 22:150-169

Hollander E, Liebowitz MR, Gorman JM, Cohen B, Fyer A, Klein DF (1989): Cortisol and sodium lactate-induced panic. Arch Gen Psychiatry 46:135-140

Kahn RS, Asnis GM, Wetzler S, van Praag HM (1988a): Neuroendocrine evidence for serotonin receptor hypersensitivity in panic disorder. Psychopharmacology (Berl) 96 360-364

Kahn RS, Trestman R, Lawlor BA, Gabriel S, Davidson M, Siever L (1994): Effects of ipsapirone in healthy subjects: a doseresponse study. Psychopharmacology (Berl) 114: 155-160

Kahn RS, Wetzler S (1991): m-Chlorophenylpiperazine as a probe of serotonergic function. Biol Psychiatry 30:1139-1166

Kahn RS, Wetzler S, van Praag HM, Asnis GM, Strauman T 
(1988b): Behavioral indications for serotonin receptor hypersensitivity in panic disorder. Psychiatry Res 25: 101-104

Kendler KS, Neale MC, MacLean CJ, Heath AC, Eaves LJ, Kessler RC (1993): Smoking and major depression. A causal analysis. Arch Gen Psychiatry 50:36-43

Kenny PJ, File SE, Rattray M (2001): Nicotine regulates 5-HT(1A) receptor gene expression in the cerebral cortex and dorsal hippocampus. Eur J Neurosci 13:1267-1271

Kirschbaum C, Wust S, Strasburger CJ (1992): 'Normal' cigarette smoking increases free cortisol in habitual smokers. Life Sci 50:435-442

Lesch KP, Disselkamp Tietze J, Schmidtke A (1990a): 5-HT1A receptor function in depression: effect of chronic amitriptyline treatment. J Neural Transm Gen Sect 80:157-161

Lesch KP, Hoh A, Disselkamp TJ, Wiesmann M, Osterheider M, Schulte HM (1991): 5-Hydroxytryptamine1A receptor responsivity in obsessive-compulsive disorder. Comparison of patients and controls. Arch Gen Psychiatry 48:540-547

Lesch KP, Mayer S, Disselkamp Tietze J, Hoh A, Wiesmann M, Osterheider M, Schulte HM (1990b): 5-HT1A receptor responsivity in unipolar depression. Evaluation of ipsapirone-induced ACTH and cortisol secretion in patients and controls. Biol Psychiatry 28:620-628

Lesch KP, Poten B, Sohnle K, Schulte HM (1990c): Pharmacology of the hypothermic response to 5-HT1A receptor activation in humans. Eur J Clin Pharmacol 39:17-19

Lesch KP, Rupprecht R, Poten B, Muller U, Sohnle K, Fritze J, Schulte HM (1989): Endocrine responses to 5-hydroxytryptamine-1A receptor activation by ipsapirone in humans. Biol Psychiatry 26:203-205

Lesch KP, Sohnle K, Poten B, Schoellnhammer G, Rupprecht R, Schulte HM (1990d): Corticotropin and cortisol secretion after central 5-hydroxytryptamine-1A (5-HT1A) receptor activation: effects of 5-HT receptor and beta-adrenoceptor antagonists. J Clin Endocrinol Metab 70:670-674

Lesch KP, Wiesmann M, Hoh A, Muller T, Disselkamp Tietze J, Osterheider M, Schulte HM (1992): 5-HT1A receptoreffector system responsivity in panic disorder. Psychopharmacology (Berl) 106:111-117

Liebowitz MR, Gorman JM, Fyer AJ, Levitt M, Dillon D, Levy G, Appleby IL, Anderson S, Palij M, Davies SO, Klein DF (1985): Lactate provocation of panic attacks, II. Biochemical and physiological findings. Arch Gen Psychiatry 42:709-719

Marks JL, Hill EM, Pomerleau CS, Mudd SA, Blow FC (1997): Nicotine dependence and withdrawal in alcoholic and nonalcoholic ever-smokers. J Subst Abuse Treat 14:521-527

Mihailescu S, Guzman MR, Drucker CR (2001): Nicotine stimulation of dorsal raphe neurons: effects on laterodorsal and pedunculopontine neurons. Eur Neuropsychopharmacol 11:359-366

Miller LG, Thompson ML, Byrnes JJ, Greenblatt DJ, Shemer A (1992): Kinetics, brain uptake, and receptor binding of tandospirone and its metabolite 1-(2-pyrimidinyl)-piperazine. J Clin Psychopharmacol 12:341-345

Miller NS, Gold MS (1998): Comorbid cigarette and alcohol addiction: epidemiology and treatment. J Addict Dis 17:55-66

Murphy DL, Mueller EA, Hill JL, Tolliver TJ, Jacobsen FM (1989): Comparative anxiogenic, neuroendocrine, and other physiologic effects of m-chlorophenylpiperazine given intravenously or orally to healthy volunteers. Psychopharmacology (Berlin) 98:275-282

Nesse RM, Cameron OG, Curtis GC, McCann DS, Huber Smith MJ (1984): Adrenergic function in patients with panic anxiety. Arch Gen Psychiatry 41:771-776

Newhouse PA, Sunderland T, Narang PK, Mellow AM, Fertig JB, Lawlor BA, Murphy DL (1990): Neuroendocrine, physiologic, and behavioral responses following intravenous nicotine in nonsmoking healthy volunteers and in patients with Alzheimer's disease. Psychoneuroendocrinology 15:471-484

NIMH (1976): Clinical Global Impressions. In: Guy W (ed), Assessment Manual For Psychopharmacology. Rockville, MD: NIMH

Oerther S, Ahlenius S (2001): Involvement of 5-HT1A and 5-HT1B receptors for citalopram-induced hypothermia in the rat. Psychopharmacology (Berl) 154:429-434

Patten CA, Rummans TA, Croghan IT, Hurt RD, Hays JT (1999): Development of depression during placebo-controlled trials of bupropion for smoking cessation: case reports. J Clin Psychiatry 60:436-441

Peroutka SJ (1985): Selective interaction of novel anxiolytics with 5-hydroxytryptamine1A receptors. Biol Psychiatry 20:971-979

Przegalinski E, Budziszewska B, Warchol Kania A, Blaszczynska E (1989): Stimulation of corticosterone secretion by the selective 5-HT1A receptor agonist 8-hydroxy2-(di-n-propylamino)tetralin (8-OH-DPAT) in the rat. Pharmacol Biochem Behav 33:329-334

Rasmussen K, Kallman MJ, Helton DR (1997): Serotonin-1A antagonists attenuate the effects of nicotine withdrawal on the auditory startle response. Synapse 27:145-152

Richmond R (1994): Beneficial effects of nicotine: fact or fiction? [comment]. Addiction 89:139-140, 144-146

Roy-Byrne PP, Uhde TW, Post RM, Gallucci W, Chrousos GP, Gold PW (1986): The corticotropin-releasing hormone stimulation test in patients with panic disorder. Am J Psychiatry 143:896-899

SAS (1989): SAS User's Guides. Cary, NC: SAS Institute Inc. Sellman JD, Wootton AR, Stoner DB, Deering DE, Craig BJ (1999): Increasing diagnosis of nicotine dependence in adolescent mental health patients. Aust N Z J Psychiatry 33:869-873

Stein EA, Pankiewicz J, Harsch HH, Cho JK, Fuller SA, Hoffmann RG, Hawkins M, Rao SM, Bandettini PA, Bloom AS (1998): Nicotine-induced limbic cortical activation in the human brain: a functional MRI study. Am J Psychiatry 155:1009-1015

Tsoh JY, Humfleet GL, Munoz RF, Reus VI, Hartz DT, Hall SM (2000): Development of major depression after treatment for smoking cessation. Am J Psychiatry 157:368-374

Villacres EC, Hollifield M, Katon WJ, Wilkinson CW, Veith RC (1987): Sympathetic nervous system activity in panic disorder. Psychiatry Res 21:313-321

Woods SW, Charney DS, Goodman WK, Heninger GR (1988): Carbon dioxide-induced anxiety. Behavioral, physiologic, and biochemical effects of carbon dioxide in patients with panic disorders and healthy subjects. Arch Gen Psychiatry 45:43-52 